\title{
PATTERNS OF EPIBIONT COVERAGE AND SUCCESSION ON MOLLUSKS FROM ST. CROIX, U.S.VIRGIN ISLANDS
}

\author{
PARSONS*, Karla M.; and BRETT, Carlton E., Dept. of Geological Sciences, \\ University of Rochester, Rochester, NY 14627 U.S.A.
}

Patterns of epibiont coverage are potentially useful tools in the determination of modern and ancient sedimentation rates as well as life habits of host organisms. A study was conducted to characterize patterns of epibiont settlement in various tropical environments and substrate types. Settling plates of clean aragonite shell were placed in six carbonate environments (beach, grass bed, bioturbated sand flat, back reef, forereef, and muddy bay) on St. Croix to document successional trends and timing of infestation by preservable, calcareous epibionts. Coralline algae were first to settle on freshly exposed substrate (within one week), followed by the foraminiferan Planorbulina and serpulid/spirorbid worm tubes. This successional order of epibiont encrustation is proposed as a measure of the length of time a shell has been exposed.

The results of this experiment were compared to epibiont patterns on naturally occurring substrates from the same environments. Because the study areas were from essentially the same reef-lagoon system, all sites were exposed to a common pool of encrusting organisms. Of primary interest were differences in encrustation on 1) varying host species, 2) rough- vs. smooth-shell surfaces, 3) infaunal vs. epifaunal shells, 4) substrates of different size, and 5) gastropods vs. bivalves. In addition, the preservability of these patterns was examined on mollusks sampled within Holocene reef cores from St. Croix.

Few preferences of epibionts for given shell-host species were noted. However, in lagoon grass-bed areas, epifaunal gastropods consistently showed greater coverage by late-stage encrusters than did infaunal bivalves. Within any environment, epibionts preferentially settled on rough substrates over smooth (e.g. heavily ribbed Codakia were more encrusted than smooth Tellina). Also, bivalve interiors were less encrusted than exteriors. While neither the interior nor exterior of these infaunal bivalves is likely to be encrusted during life, the interior of both species remained less encrusted, perhaps controlled by the smooth nature of the shell interior.

Differences in both the abundance and diversity of epibiont faunas were noted between substrates of different size. Epibiont faunas from mollusk shells smaller than 8 $\mathrm{cm}$ had fewer epibiont species than did coral substrates at least $15 \mathrm{~cm}$ across. The foram Gypsina, a white sheet-like encruster, and several species of bryozoa, all late-stage encrusters, were more successful on larger substrates from the same environments. This may be controlled by the successional patterns described above. Larger substrates were presumably exposed longer and thus acquired a higher diversity of encrusting species, thereby allowing some encrusters to spread over more area. Size differences exerted more control on epibiont coverage than did substrate type (i.e. coral vs. mollusk). The primary control of epibiont coverage, therefore, was the length of time a shell was exposed. Substrate-selective patterns were not as great as those occurring between environments.

Shells recovered from reef cores looked very much like those described from the reef surface. The occurrence of mollusk remains throughout the cores, along with a $5700 \pm 70$ ybp radiocarbon date from a Chione valve from the bottom of one core, indicates that these are not simply recent shells that have fallen into the reef interior. Therefore, epibiont coverage has high potential for being preserved on shells caught up in the accreting reef. 